\title{
Molecular Identification of Etiological Agents of Chromoblastomycosis in Costa Rica
}

\section{Daniela Jaikel-Víquez ${ }^{1,2 *}$, Stefany Lozada-Alvarado ${ }^{1,3}$ and Lorena Uribe-Lorío ${ }^{4}$}

${ }^{1}$ Section of Medical Mycology, Department of Clinical Microbiology and Immunology, School of Microbiology, University of Costa Rica, Ciudad Universitaria Rodrigo Facio Brenes, San Pedro, Costa Rica

${ }^{2}$ Center for Research in Tropical Diseases (CIET), Faculty of Microbiology, University of Costa Rica, Ciudad Universitaria Rodrigo Facio Brenes, San Pedro, Costa Rica

${ }^{3}$ Clinical Laboratory and Blood Bank, University of Costa Rica (LCBSUCR), University of Costa Rica, San José, Costa Rica

${ }^{4}$ Center for Research in Cellular and Molecular Biology (CIBCM), School of Agronomy, University of Costa Rica, Ciudad Universitaria Rodrigo Facio Brenes, San Pedro, Costa Rica

*Corresponding Author: Daniela Jaikel-Víquez, Section of Medical Mycology, Department of Clinical Microbiology and Immunology, School of Microbiology, University of Costa Rica, Ciudad Universitaria Rodrigo Facio Brenes, San Pedro, Costa Rica.
Received: March 10, 2020

Published: April 14, 2020

(C) All rights are reserved by Daniela

Jaikel-Víquez., et al.

\begin{abstract}
Chromoblastomycosis is the second most frequently reported subcutaneous mycosis in Costa Rica. It is caused by dematiaceous fungi belonging to the family Herpotrichiellaceae (Order Chaetothyriales), especially by Fonsecaea pedrosoi and Cladophialophora carrionii. However, it is important to note that Fonsecaea monophora is able to disseminate and cause cerebral phaeohyphomycosis. Thus, five clinical isolates deposited in the Fungal Collection of the School of Microbiology of the University of Costa Rica were analyzed. The isolates were characterized macroscopically and microscopically after grown in potato dextrose agar. Genetic identification was performed via amplification and sequencing of the ITS (internal transcription spacer) region. The isolates were identified as F. pedrosoi ( $\mathrm{n}=3)$, F. monophora $(\mathrm{n}=1)$ and Rhinocladiella aquaspersa $(\mathrm{n}=1)$. Hence, we report for the first time that $R$. aquaspersa is an etiological agent of chromoblastomycosis in Costa Rica and confirm the presence of both F. pedrosoi and F. monophora in the country. Therefore, we recommend the usage of molecular techniques to identify these pathogens since there is a risk of fungal dissemination in our patients.
\end{abstract}

Keywords: Chromoblastomycosis; Chromomycosis; Fonsecaea monophora; Fonsecaea pedrosoi; Rhinocladiella aquaspersa; Subcutaneous Infections

\section{Abbreviation}

ITS: internal transcription spacer

\section{Introduction}

Chromoblastomycosis is a worldwide disease, however, most cases are reported in tropical and subtropical areas, especially in Latin America [1-5]. It is the second most frequently reported subcutaneous mycosis in Costa Rica, surpassed only by sporotrichosis [6,7]. Thus, in 1953, Costa Rica ranked third in incidence ( $\mathrm{n}=53$ cases), below Brazil and Cuba [2].

It is a cutaneous and subcutaneous infection that is obtained by traumatic inoculation of organic material contaminated with dematiaceous fungi. It usually affects lower limbs and is slowly evolving as the infection grows approximately one centimeter per year. A papule or plaque appears at the site of inoculation, which then acquires a verrucous form. Older lesions can ulcerate, become infected secondarily, and eventually culminate in squamous cell carcinoma. Also, lesions in the form of atrophic plaque have been described. In direct examinations (potassium hydroxide or histological stains) Medlar bodies are observed [1-5].

The etiologic agents are from the Herpotrichiellaceae family (order Chaetothyriales) among which are the species Fonsecaea spp., Cladophialophora carrionii, Phialophora verrucosa, Exophiala jeanselmei and Rhinocladiella aquaspersa [8-15]. In regard to the 
genus Fonsecaea, the usage of molecular biology has discerned that it is composed of several species, being those of medical importance: F. pedrosoi, F. monophora and F. nubica [16]. This is of great importance because at the microscopic level these fungi are very similar, however, the pathology they cause differs. F. pedrosoi and F. nubica are exclusive causative agents of chromoblastomycosis, while F. monophora can cause other clinical conditions such as cerebral phaeohyphomycosis [17-19] and/or spread to lymph nodes, lungs, kidneys and liver [17]. Hence, the diversity and complexity of the clinical manifestations caused by F. monophora is the reason why various groups of researchers, worldwide, have been given the task of characterizing at the molecular level all those isolates previously identified as $F$. pedrosoi, by light microscopy techniques. For example, Yaguchi et al. (2007) [17], analyzed 20 Japanese strains of which $100 \%$ were identified as F. monophora and 21 Latin American strains, of which 47.62\% (n = 10) were identified as F. pedrosoi and $33.33 \%(n=7)$ as F. monophora. Similar results were published by de Hoog., et al. (2004) [10] and by Najafzadeh., et al. (2009) [11].

To date, no work has been carried out in Costa Rica that continue with these international initiatives. This is essential since the study of Yaguchi et al. (2007) [17] analyzed three Costa Rican clinical isolates out of which one was molecularly identified as F. monophora, thus proving the existence of this fungus in our country. In turn, it is very important to know which are the causative agents of this pathology and to evaluate whether these fungi can also be potential agents of invasive phaeohyphomycosis. Therefore, the present study aims to identify by molecular biology techniques the isolated chromoblastomycosis causing fungi from the collection of the Medical Mycology Laboratory of the School of Microbiology, University of Costa Rica.

\section{Materials and Methods}

\section{Clinical isolates}

Five Costa Rican clinical isolates, from patients suffering chromoblastomycosis were analyzed; these isolates were deposited in the Fungal Collection of the Section of Medical Mycology of the School of Microbiology, University of Costa Rica. The fungi were kept in potato dextrose agar (PDA), with a layer of mineral oil and at room temperature $\left(20-30^{\circ} \mathrm{C}\right)$. Fonsecaea pedrosoi CBS 659.76 and F. monophora CBS 269.37 were used as control strains.

\section{Phenotypic characterization}

A drop of clear lactophenol reagent was placed on a slide and then a small portion of the fungal colony was placed on top of it, then, the preparation was covered with a coverslip and slightly heated in the flame, without boiling. Finally, the preparation was observed under a microscope (400x) so that the typical morphology of each fungus could be observed [20].

\section{DNA extraction and amplification}

DNA extraction was perform using The Nucleo Spin ${ }^{\circledR}$ Tissue kit (Macherey-Nagel, Germany), following manufacturer procedure. The internal transcription spacer (ITS) was amplificated according to the protocol described by White., et al. (1990) [21], using the following pair of primers: ITS1 (5'-TCC GTA GGT GAA CCT GCG G-3 ') [forward] and ITS4 (5' -TCC TCC GCT TAT TGA TAT GC-3 ') [reverse]. The PCR products were sent to Macrogen Inc. (South Korea), where the sequencing process was carried out. The sequences obtained were reviewed and edited using the BioEdit v 7.0.5.2 [22] and aligned with reference sequences from the NCBI database in MEGA [23]. Multiple sequence alignments were performed with ClustalX [24]. Phylogenetic trees were constructed using Bayesian Inference through the MrBayes 3.2.6 program; 1000 replicates were analyzed; the resampling percentage was reflected in each branch of the tree.

\section{Results and Discussion}

Clinical isolates and phenotypic characterization

Chromoblastomycosis is the second most frequently reported subcutaneous mycosis in Costa Rica, preceded only by sporotrichosis. As for its epidemiology, most cases occur in adult male patients and the lesions are located in the lower limbs [14]. The isolates analyzed in this study mostly come from male patients, but it is important to highlight that the majority of the patients had lesions in their upper limbs; situation which, although not common, has also been reported in the literature $[12,25,26]$. Demographic data of the patients is found in table 1. Only the isolate FOPE 26 had information of the year in which it was deposited in the fungal collection: 2002. Macroscopic morphology of the fungal cultures was composed of black and velvety texture colonies. At the microscopic level, the isolates FOPE 02, 17, 22 and 26 presented dematiaceous, septate mycelium with the presence of branched conidiophores, simple acroteca-type conidiophores and/or phyalid-type conidiophores; meanwhile, FOPE 04 presented dematiaceous, septate mycelium with the presence of only simple acroteca-type conidiophores (Figure 1).

\section{Molecular identification}

Prior to this work, Costa Rican studies focused only on the morphological identification of the etiological agents of chromoblastomycosis $[8,13,14]$, where those fungi that presented dematiaceous, 


\begin{tabular}{|c|c|c|c|c|}
\hline \multirow[b]{2}{*}{ Isolate } & \multirow{2}{*}{$\begin{array}{c}\text { Preliminary } \\
\text { identification* }\end{array}$} & \multirow{2}{*}{$\begin{array}{l}\text { GenBank } \\
\text { access } \\
\text { code }\end{array}$} & \multicolumn{2}{|c|}{$\begin{array}{c}\text { Patient } \\
\text { Demographics }\end{array}$} \\
\hline & & & Gender & $\begin{array}{l}\text { Anatomical } \\
\text { site of the } \\
\text { lesion }\end{array}$ \\
\hline FOPE 02 & Fonsecaea sp. & MH374865 & Female & Arm \\
\hline FOPE 04 & Rhinocladiella sp. & MH374866 & NI & Arm (elbow) \\
\hline FOPE 17 & Fonsecaea sp. & MH374872 & Male & Little finger \\
\hline FOPE 22 & Fonsecaea sp. & MH374867 & Male & Right ankle \\
\hline FOPE 26 & Fonsecaea sp. & MH374868 & Male & Leg \\
\hline
\end{tabular}

Table 1: Preliminary identification of the isolates analyzed and demographic data of patients with chromoblastomycosis from which they were obtained.

*: Microscopic identification of the saprophytic phase.

NI: Not Indicated.

septated mycelium with the presence of two or three of the following types of asexual sporulation: branched conidiophores, simple acroteca-type conidiophores and simple phyalid-type conidiophores were classified as members of the genus Fonsecaea. However, in 2004, de Hoog., et al. [10] studied Fonsecaea isolates based on the analysis of their ITS sequences and random amplification of polymorphic DNA (RAPD), finding a high diversity and proposing the separation of the genus in two species: F. pedrosoi and $F$. monophora. Over the years, new studies have defined two more species: F. nubica and Fonsecaea multimorphosa.

Species-level identification is related to the pathology they cause, with F. pedrosoi and F. nubica been exclusive agents of chromoblastomycosis, and F. monophora and F. multimorphosa causing cerebral phaeohyphomycosis in immunocompetent patients and felines, respectively $[17,19,27]$. On the other hand, fungal infections at the brain level caused by hyaline fungi such as Cryptococcus spp., Aspergillus spp., Fusarium and Mucorales are mostly associated with immunosuppressive patients [28-30].

The sequences obtained were deposited in GenBank. The access codes are shown in table 1 . The phylogenetic analysis was performed using type strain sequences in order to estimate with greater certainty the taxonomy of the clinical isolates. The analysis grouped the isolates sequences under study into three groups: $\mathrm{n}$ $=3$ were identified as $F$ pedrosoi, $\mathrm{n}=1$ as $F$ monophora and $n=1$ as $R$. aquaspersa (Figure 1). The evolutionary history was inferred using Bayesian Inference. The consistency index is (0.953271), the retention index is (0.985549), and the composite index is 0.959884 (0.939495) for all sites and parsimony-informative sites (in paren-

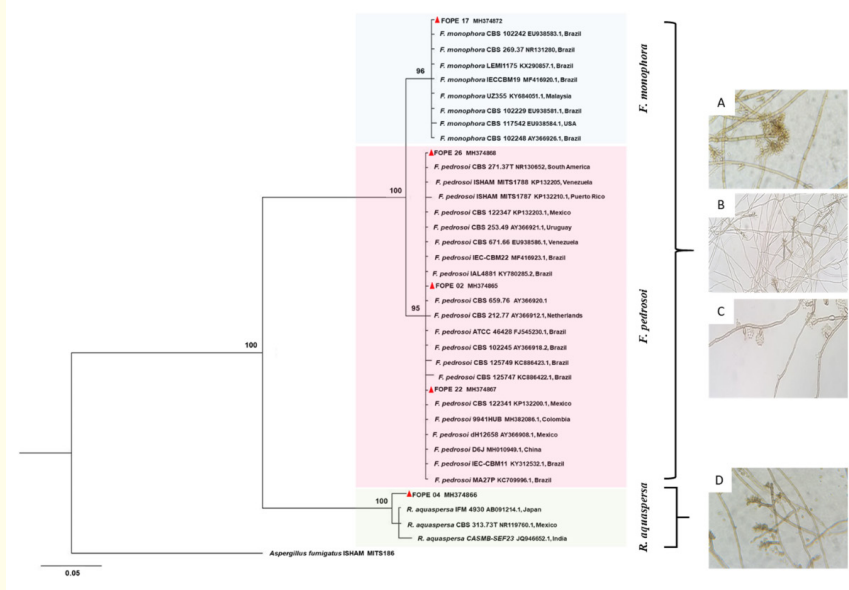

Figure 1: Phylogenetic tree constructed with the ITS sequence obtained by Bayesian Inference. 1000 replicates were analyzed, the bootstrap percentage is shown on each branch of the tree. The red triangles show the Costa Rican isolates. The forms of asexual sporulation of the aetiological agents of chromoblastomycosis, found in this study are: (A) branched conidiophore, (B, D) simple acroteca-type conidiophore and $(\mathrm{C})$ phyalid-type conidiophore.

theses). The percentage of replicate trees in which the associated taxa clustered together in the bootstrap test (1000 replicates) are shown next to the branches.

F. pedrosoi is the most frequently isolated species from chromoblastomycosis lesions worldwide $[10,11,17,31,32]$, so it is not surprising that $60 \%$ of the isolates from this study were identified as this species. On the other hand, Yaguchi., et al. (2007) [17], reclassified a clinical isolate from Costa Rica from F. pedrosoi to F. monophora (GenBank access code AB117978 by ITS and AB253501 by cytochrome b sequencing), evidencing its presence in the country; data which was corroborated in this study. In turn, being Costa Rica a tropical country that has a high microbial diversity, it is expected that the other genera that cause this disease are also present. For example, Mora and collaborators reported in 2010 the first Costa Rican clinical case of chromoblastomycosis caused by $C$. carrionii [26] and we are currently describing the first case caused by $R$. aquaspersa.

Regarding the phylogenetic analysis, the tree obtained showed a separation of genera and species in clades with good statistical support $(100 \%$ bootstrap). The retention index shows that the differences in the tree are in the internal nodes and that the isolates under study were generated from the same common ancestor. 
When comparing the sequences of Fonsecaea spp. with those existing in the GenBank database, we found similarities with sequences from Latin American countries such as Brazil and Mexico. This phenomenon could be attributed to the possible similarity of ecosystems in tropical countries where the fungus can develop. However, in the case of $R$. aquaspersa, there is a greater relationship with sequences from Japan, Mexico and India. Finally, the molecular biology of pathogenic fungi has provided increasingly valuable information regarding the distribution and presence of previously unknown species.

\section{Conclusion}

F. pedrosoi, F. monophora and R. aquaspersa were identified as etiological agents of chromoblastomycosis in Costa Rica. Hence, the standardization of a methodology to differentiate Fonsecaea species would represent a better clinical approach, since it would be known if the causative agent of the patients' disease has the capacity to disseminate or not.

\section{Acknowledgements}

This study was funded by Vicerrectoría de Investigación, University of Costa Rica: projects N $803-B 2-105$ and 430-B7-732.

\section{Conflict of Interest}

The authors declare that there is no conflict of interest involved in this article.

\section{Bibliography}

1. Rippon JW. "Micología Médica". $3^{\text {rd }}$ edition. México DF: Nueva Editorial Interamericana; (1990).

2. Burstein Z. "Cromomicosis: Clínica y tratamiento; situación epidemiológica en Latinoamérica". Revista Peruana de Medicina Experimental y Salud Pública 21.3 (2004): 167-175.

3. López R., et al. "Chromoblastomycosis". Clinical Dermatology 25 (2007): 188-194.

4. Salas I. "La cromoblastomicosis". Revista del Colegio de Microbiólogos y Químicos Clínicos de Costa Rica 13.2 (2007): 40-43.

5. Bonifaz A. "Micología Médica Básica". $4^{\text {th }}$ edition. México DF: Editorial McGraw-Hill Interamericana editores (2012).

6. Astorga E., et al. "Cromomicosis. Nuevos casos de cromomicosis tratados con anfotericina By 5-fluorocitosina en forma simultánea". Revista Médica de Costa Rica 470 (1980): 17-22.
7. Alice E. "Ecología de Sporothrix schenckii". Revista Médica de Costa Rica 479 (1982): 81-86.

8. Romero A, Trejos A. "La cromoblastomicosis en Costa Rica”. Revista de Biología Tropical 1.2 (1953): 95-115.

9. Trejos A. "Cladosporium carrionii n. sp. and the problem of Cladosporia isolated from chromoblastomycosis". Revista de Biología Tropical 2.1 (1954): 75-112.

10. De Hoog G., et al. "Molecular ecology and pathogenic potential of Fonsecaea species". Medical Mycology 42 (2004): 405-417.

11. Najafzadeh MJ., et al. "Genetic diversity and species delimitation in the opportunistic genus Fonsecaea". Medical Mycology 47 (2009): 17-25.

12. Badali H., et al. "Rhinocladiella aquaspersa, proven agent of verrucous skin infection and a novel type of chromoblastomycosis". Medical Mycology 48 (2010): 696-703.

13. Mora M., et al. "Cromoblastomicosis por Cladophialophora carrionii: primer caso descrito en literatura costarricense". Revista Médica de Costa Rica y Centroamérica 894 (2010): 373376.

14. Soto-Trejos L., et al. "Cromoblastomicosis: Situación en Costa Rica”. Revista Médica de Costa Rica y Centroamérica 71.613 (2014): 737-744.

15. Shi D., et al. "Chromoblastomycosis due to Fonsecaea monophora misdiagnosed as sporotrichosis and cutaneous tuberculosis in a pulmonary tuberculosis patient". Medical Mycology Case Report 11 (2016): 57-60.

16. Najafzadeh MJ., et al. "Molecular epidemiology of Fonsecaea species". Emerging Infectious Diseases 17.3 (2011): 464-469.

17. Yaguchi T., et al. "Molecular phylogenetics of strains morphologically identified as Fonsecaea pedrosoi from clinical specimens". Mycoses 50 (2007): 255-260.

18. Koo S., et al. "Fonsecaea monophora cerebral phaeohyphomycosis: case report of successful surgical excision and voriconazole treatment and review". Medical Mycology 48 (2010): 769-774.

19. Stokes W., et al. "Case report of cerebral phaeohyphomycosis caused by Fonsecaea monophora". JAMM (2017). 
20. Gross-Martínez NT.., et al. "Métodos diagnósticos en micología médica". $1^{\text {st }}$ edition. San José: Editorial UCR (2012).

21. White TJ., et al. "Chapter 38: Amplification and direct sequencing of fungal ribosomal RNA genes for phylogenetics". In: PCR Protocols: A Guide to Methods and Applications: Academic Press Inc (1990).

22. Hall TA. "Bio Edit: a user-friendly biological sequence alignment editor and analysis program form Windows 95/98/NT". Nucleic Acids Symposium Series 41 (1999): 95-98.

23. Tamura K., et al. "MEGA6: molecular evolutionary genetics analysis version 6.0." Molecular Biology and Evolution 30 (2013): 2725-2729.

24. Larkin MA., et al. "Clustal $\mathrm{W}$ and Clustal X version 2.0." Bioinformatics 23 (2007): 2947-2948.

25. Pires CAAA., et al. "Clinical, epidemiological and mycological report on 65 patients from the Eastern Amazon region with chromoblastomycosis". Brazilian Annals of Dermatology 87.4 (2012): 555-560.

26. González GM., et al. "Chromoblastomycosis caused by Rhinocladiella aquaspersa”. Medical Mycology Case Report 2 (2013): 148-151.

27. Najafzadeh MJ., et al. "Fonsecaea multimorphosa sp. nov, a new species of Chaetothyriales isolated from a feline cerebral abscess". Fungal Biology 115 (2011): 1066-1076.

28. Criado IS., et al. "Acute hydrocephalus as a presentation form of disseminated aspergillosis". Enfermedades Infecciosas y Microbiología Clínica 30.6 (2012): 348-355.

29. Sreedharan PE., et al. "Disseminated Fusarium oxysporum neurospinal infection". Indian Journal of Orthopedia 48.2 (2014): 220-222.

30. Jaikel-Víquez D., et al. "Tipificación molecular y susceptibilidad in vitro frente a fluconazol de aislamientos clínicos costarricenses del complejo Cryptococcus neoformans/Cryptococcus gattii". Revista Panamericana de Enfermedades Infecciosas 1.1 (2018):12-20.

31. Ventura-Flores R., et al. "Cromoblastomicosis: características clínicas y microbiológicas de una enfermedad desatendida”. Revista Chilena de Infectología 34.4 (2017): 404-407.
32. Le TA., et al. "Case Report: A case of chromoblastomycosis caused by Fonsecaea pedrosoi in Vietnam". Mycopathologia 184 (2019): 115-119.

\section{Assets from publication with us}

- Prompt Acknowledgement after receiving the article

- Thorough Double blinded peer review

- Rapid Publication

- Issue of Publication Certificate

- High visibility of your Published work

Website: https://www.actascientific.com/

Submit Article: https://www.actascientific.com/submission.php Email us: editor@actascientific.com

Contact us: +919182824667 